\title{
Tecnología CRISPR-Cas9: una herramienta aplicable en la agricultura de Costa Rica
}

\author{
ANDRÉs ZÚNIIGa Orozco' \\ Docente e Investigador de la carrera Ingeniería Agronómica, Escuela de Ciencias Exactas y Naturales, Universidad \\ Estatal a Distancia. Apdo. 474-2050 San Pedro, San José, Costa Rica. Correo: azunigao@uned.ac.cr \\ Teléfono: (506) 22021813.
}

Recibido: 06 setiembre 2017

Aceptado: 02 octubre 2017

\section{RESUMEN}

En la actualidad la técnica de biología molecular CRISPRCas9, es la más estudiada a nivel global para la edición genómica. Por su facilidad, adaptabilidad, versatilidad, precisión y costo relativamente bajo es una tecnología que puede cambiar el panorama en la agricultura. El objetivo de este artículo es hacer una reseña y descripción acerca de la tecnología CRISPR-Cas9, mencionar algunas aplicaciones que se han realizado en la agricultura y citar algunas posibilidades que serían aplicables en Costa Rica.

Palabras clave: CRISPR-Cas9, agricultura, biotecnología, genética.

\begin{abstract}
At present the technology of molecular biology CRISPRCas9, it is the most studied worldwide for the genomic edition. Because of its ease, adaptability, versatility, precision and relatively low cost is a technology that can change the landscape in agriculture. The aim of this article is to do a review and description about the CRISPR-Cas9 technology, to mention some applications that have been realized in agriculture and to mention some possibilities that would be applicable in Costa Rica.
\end{abstract}

Key words: CRISPR/Cas9, agriculture, biotechnology, genetics.

\section{Mejoramiento Genético con el desarrollo de la Revolución Verde}

La Organización de las Naciones Unidas para la Agricultura y la Alimentación (FAO) (1996) y Echarri (1998) describen a la Revolución Verde como una serie de acontecimientos que, además del aumento en rendimiento en algunos cultivos como arroz, trigo y maíz, se incorporaron una serie de tecnologías que permitieron aprovechar al máximo el rendimiento potencial de los cultivos, en las condiciones a que estaban sometidos los agricultores en los países en desarrollo. Los progresos científicos se vieron favorecidos por un notable crecimiento de los sectores comerciales que suministraban insumos a la agricultura. El desarrollo de nuevas variedades de cultivos, el conocimiento adquirido en algunos conceptos como vigor híbrido (Beal 1880), desarrollo de líneas puras (Shull 1908 y 1909, Jones 1918), los bancos de germoplasma y el interés por aumentar la productividad potenciaron el uso del mejoramiento genético convencional como parte de las tecnologías al servicio de los productores durante ese periodo.

La bonanza de la Revolución Verde comenzó a declinar en la década de los años 80-90, cuando se registraron estudios que describían y evidenciaban la contaminación e impacto ambiental de las tecnologías utilizadas hasta ese momento, y de cómo habían generado efectos negativos en el ambiente, la vida silvestre e incluso en la salud humana (Ceccon 2008; Eckholm 1978 y Freebairn 1995). Al margen de los efectos positivos y negativos que tuvo la Revolución Verde como lo relatan muchos organismos internacionales, gobiernos, activistas, agrupaciones agropecurias, productores y la sociedad civil, es importante rescatar que fue el inicio del advenimiento de una serie de tecnologías en mejoramiento genético que marcaron la pauta a seguir durante los años siguientes. 


\section{Tecnologías desarrolladas como herramientas en mejoramiento genético}

Algunas tecnologías emergentes desarrolladas para mejoramiento genético han logrado ser muy exitosas, como es el caso de las mutaciones inducidas e inducción de poliploides en las cuales se espera obtener variabilidad del material genético. El cultivo de anteras es otra técnica que se usa para el desarrollo de líneas puras, dando como resultado líneas conocidas como haploides, lo cual vino a mostrar caracteres en su condición homocigota más fácilmente y con esto contribuir en acortar el periodo de desarrollo de variedades.

Una técnica muy utilizada es el rescate o cultivo de embriones, el cual consiste en cultivar éstos mismos invitro en etapas tempranas para superar barreras poscigóticas, las cuales en ocasiones son impedimento y generan diferentes grados de incompatibilidad en cruzamientos interespecíficos, estos cruces biparentales se han utilizado normalmente junto a cruzamientos "puente", este último involucrando más de 2 especies, pero con el mismo fin, trasladar genes de una especie a otra. El origen del trigo fue el resultado del uso de ésta técnica, usando especies "puente"; posteriormente los investigadores hicieron una modificación a esta técnica utilizando los embriones para facilitar la compatibilidad entre especies.

Recientemente se ha implementado el uso de marcadores moleculares, los cuales vinieron a favorecer el proceso de selección. Este método se ha utilizado para identificar genes de tolerancia a ciertas enfermedades en muchos cultivos. La producción de híbridos somáticos ha sido otra de las técnicas utilizadas en laboratorio, la cual consiste en fusionar dos células provenientes de diferentes especies, esta es una técnica que han utilizado los desarrolladores de productos transgénicos.

A partir de la década de los 90 se inició la revolución de los productos transgénicos por medio de diversas técnicas en las cuales, se incorporan algunos genes de una especie vegetal relacionada a un cultivo determinado o también se presenta el caso en que se incorporan algunos genes a un cultivo determinado siendo el donador perteneciente a otro reino de organismos distintos al vegetal. Esta técnica biotecnológica ha ocasionado diversas reacciones en la comunidad científica, en organizaciones ambientalistas, gobiernos y la sociedad civil, habiéndose encontrado grupos polarizados a favor y en contra. A pesar de que los transgénicos son una técnica que ha ocasionado reacciones tan diversas según cada país, sector, legislación y consumidor, es indiscutible que abrió una gran discusión con una heterogeneidad de actores, los cuales enriquecieron mucho el discurso y favorecieron las posiciones científicas que actualmente se argumentan con respecto a este tema $\mathrm{y}$ con respecto al rumbo que deben tomar las nuevas tecnologías en el mejoramiento genético. Fruto de la discusión científica generada se comenzó a investigar en la tecnología CRISPRCas9, Clustered Regularly Interspaced Short Palindromic Repeats, en español "Repeticiones Palindrómicas Cortas Agrupadas y regularmente Interespaciadas", pareciera difícil de entender, pero realmente es más sencillo de lo que aparenta según veremos más adelante.

\section{CRISPR-Cas9: sus orígenes}

A inicios de los años 80 se descubrió en la bacteria Escherichia coli (Bolivar et al. 1977), el mecanismo por el cual se defendían de algunos virus. En 1987 se confirmó el mismo mecanismo en la bacteria Streptococcus pyogenes (Dciencia 2015) y en 2007 (Barrangou et al. 2007) con la bacteria Streptococcus thermophilus se demostró que la bacteria podía adquirir resistencia contra bacteriófagos integrando un fragmento del genoma de un virus dentro de su locus CRISPR. Posteriormente se identificaron 4 mecanismos de defensa siendo el II el más estudiado por su simplicidad y adaptabilidad para la edición genómica (Reis A., Hornblowe B., Robb B., Tzertzinis G. 2014). No fue hasta el 2011 cuando por primera vez se logró dilucidar como modificar el genoma de E.coli con base en la secuencia de resistencia identificada en S.thermophilus para adquirir inmunidad a la transformación 
de plasmidos (Sapranauskas et al. 2011), estudio que luego se comprobó y ejecutó en 2012 con los trabajos de Jinek et al. (2012). Este hito científico se basó en los trabajos de Mojica FJ, Diez-Villasenor C, García-Martinez J y Soria E. (2005), Barrangou et al. (2007), Brouns et al. (2008), Marraffini y Sontheimer (2008), Hale et al. (2009), Haft DH, Selengut J,Mongodin EF y Nelson KE (2005), Pul et al. (2010) y Garneau et al. (2010) donde se habían estudiado y dilucidado los mecanismos previos.

Una vez concretado este paso se abrió un abanico de opciones y aplicaciones para la modificación genómica de precisión en cualquier organismo biológico con esta tecnología, la cual fue nombrada como: CRISPR-Cas9.

\section{¿En qué consiste la tecnología CRISPR-Cas9?}

Después de dilucidar los 4 mecanismos de defensa principal que tienen las bacterias contra los virus, el mecanismo II ha sido el más ampliamente estudiado. El complejo CRISPR-Cas9 tiene dos componentes, el primero es una enzima (Cas9) que funciona como una tijera para cortar ADN (en la naturaleza las bacterias la usan para desarmar el genoma de virus invasores), el otro componente (CRISPR) es un ARN que guía a las "tijeras" hacia una secuencia de nucleótidos específica que ha sido enviada a cortar, a esta secuencia se le conoce como objetivo o target. Una vez encontrado el objetivo o target, la Cas9 abre la cadena de ADN y deja la puerta abierta para que se modifique la secuencia de nucleótidos. Podemos observar en la figura 1 una representación básica del procedimiento:

Este sistema de defensas utilizado por algunas bacterias, como se explicó anteriormente, incluso va más allá, las proteínas Cas son capaces de tomar una pequeña parte del ADN viral, modificarlo e integrarlo dentro del conjunto de secuencias CRISPR. De esa forma, si esa bacteria (o su descendencia) se encuentra con ese mismo virus ahora inactivará de forma mucho más eficiente el material genético viral. Es, por lo tanto, un verdadero sistema inmune de bacterias.

La tecnología CRISPR-Cas9 es una herramienta molecular que viene a ser utilizada para "editar" o "corregir" el genoma de cualquier célula, gracias a ese mecanismo dilucidado en bacterias. Eso incluye, claro está, desde células de bacterias, virus, hongos, plantas, animales y las células humanas. Algunos autores lo mencionan analógicamente como unas "tijeras" moleculares que son capaces de cortar cualquier molécula

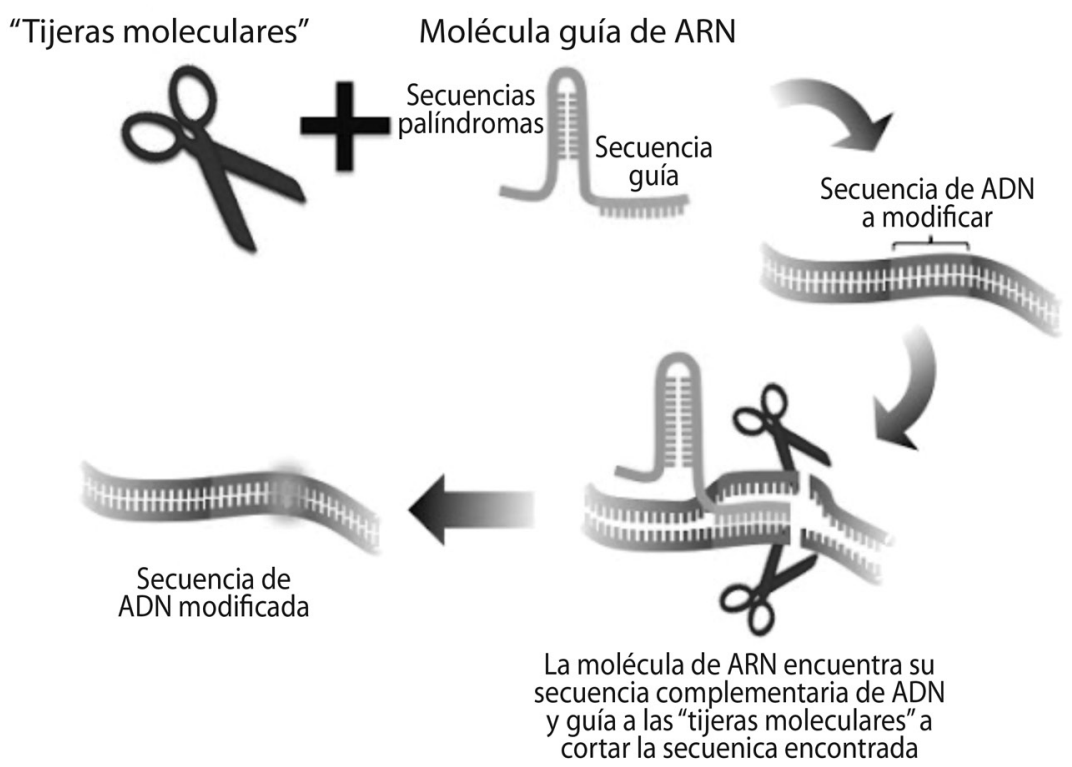

Figura 1. Representación gráfica de la tecnología CRISPR/Cas9. Fuente: Bernal-Franco D. (2015). 
de ADN, haciéndolo además de una manera muy precisa y totalmente controlada. Esa capacidad de cortar el ADN es lo que permite modificar su secuencia, eliminando o insertando nuevo ADN (Hobbs 2016, Dciencia 2015 y Specter 2016).

Según Opazo (2016), entre las ventajas de la tecnología podemos citar que es barata, incrementa la rapidez para obtener resultados, precisa, puede eliminar la transgénesis y el debate en torno a este tema, entendiendo su mecanismo debería reducir los obstáculos regulatorios en los países y la rápida evolución le ha permitido, incluso a PYMES (Pequeñas y Medianas Empresas), desarrollar la aplicación.

\section{Aplicaciones}

En la figura 2 se observa una de las primeras aplicaciones en cultivos, Soyk et al. (2017) encontraron que el mejoramiento convencional produjo un exceso de flores y frutos pequeños (Figura 2, derecha), los cuales muchas veces no llegan a llenar y más bien contribuyen a drenar los fotoasimilados. Los investigadores están modificando la arquitectura de la inflorescencia para ajustar la cantidad de flores y frutos para cada tipo de tomate, sea tipo bola (Figura 2, imagen del medio) o tipo cherry (Figura 2, izquierda), lo anterior con el fin de evitar pérdidas y aumentar rendimiento, lo cual inevitablemente mejorará la rentabilidad.

Con la aplicación explicada anteriormente vemos como con CRISPR-Cas9, se ha creado un nuevo tipo de poder disponible para la especie humana, por primera vez los científicos pueden rápida y precisamente alterar, borrar o reorganizar todos los organismos vivos, incluyendo al ser humano.

Las aplicaciones dilucidadas con esta tecnología tienen la amplitud de la imaginación que
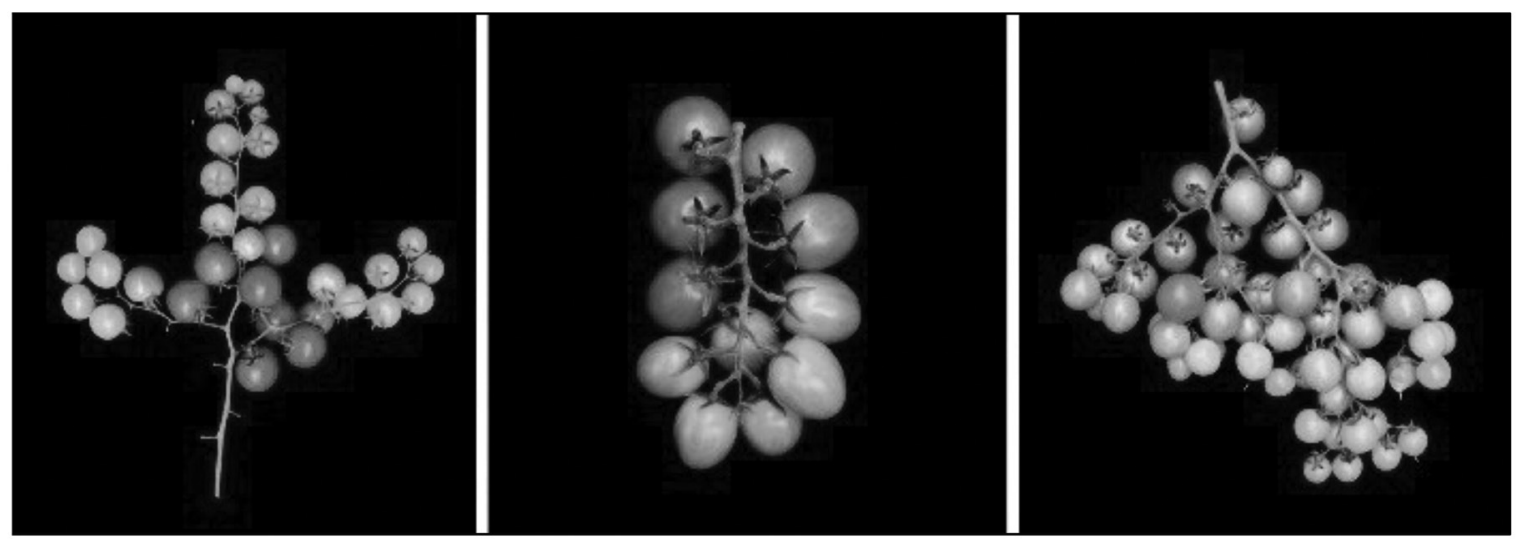

Figura 2. Tomate (Solanum lycopersicum) modificado en la arquitectura de la inflorescencia y frutos por medio de la técnica CRISPRCas9. Fuente: Soyk et al. (2017).

alcance entre los científicos, gobiernos, sectores productivos, salud pública, conservación, medio ambiente y en general todos los sectores que trabajen con organismos biológicos. La intención de esta revisión es mencionar algunas de las aplicaciones en las que se está utilizando actualmente, principalmente en el sector agrícola, pero la posibilidad general es muy amplia.

En salud pública, el científico Anthony James de la universidad de California, inició un proyecto de trascendencia mundial para erradicar la Malaria modificando el ADN del mosquito vector (Anopheles gambiae) para adquirir inmunidad a ser infectado por el agente patógeno. En otras investigaciones recientes se está iniciando un equipo de especialistas que trabajen con la manipulación del virus del VIH, modificando el ADN humano; también con el enfoque de salud pública, se está trabajando en eliminar la susceptibilidad a virus en órganos de cerdos 
para hacerlos compatibles con el ser humano (Specter 2016).

Recientemente también se ha iniciado protocolos para la modificación de células humanas con los trabajos realizados por Mali et al. (2013), lo cual, ha abierto el debate global acerca de las implicaciones bioéticas, de hecho nunca antes una tecnología emergente ha puesto en discusión la posibilidad tan real de modificar el ADN humano, sin embargo, tendrá que superar muchos foros científicos donde se discuta hasta qué punto es bueno el alcance de la misma; los resultados podrían poner freno a sus aplicaciones, debido a que, no necesariamente todos los campos de la biología deberían ser autorizados para la modificación genómica, especialmente en genética humana explora la brecha de intervenir la "esencialidad" de la especie si se usa indebidamente.

En el sector agrícola se ha registrado en Estados Unidos, la legalización y comercialización de hongos que no se oxidan (Opazo 2016). La empresa Cellectis Plant Sciences está desarrollando una papa que tenga mayor vida poscosecha y se pueda freír sin acumular acrilamida, sustancia que se cree tener un efecto cancerígeno. Esta papa se ha creado en tan solo 1 año, mientras que por métodos convencionales tardaría entre 5-10 años y ha costado diez veces menos que producir maíz o soya transgénica (Regalado 2015).

Sorprendentemente, después de 6 años de ser anunciada esta tecnología, se comenzó a trabajar en cómo aumentar la productividad modificando la fotosíntesis, lo cual representa todo un reto al ser genética cuantitativa, este es el caso de modificar la fotosíntesis C3 para convertirla en C4 en cultivos como arroz (Bullis 2015).

El siguiente paso será cambiar las letras del ADN de los genes de las plantas, cambiando la versión de un gen en una planta por la de otra que se sabe que es resistente a una enfermedad, comúnmente se le ha llamado terapia génica. Este es el caso del trigo donde se viene realizando investigaciones para hacerlo resistente al oidio o mildiú (Wang et al. 2015 y AcevedoGarcía et al. 2016).
Para Costa Rica hay aplicaciones potenciales para aplicar esta tecnología, se citan los siguientes casos por el impacto que podrían generar en el sector:

- En cítricos: crear la capacidad para desactivar genes receptores del virus huanglongbing (HLB) en psílidos (Diaphorina citri) que atacan a este cultivo.

- En tomate: crear la capacidad para desactivar genes receptores del virus de la cuchara en especies de mosca blanca (Bemisia tabaci y Trialeurodes vaporariorum), las cuales atacan plantaciones de tomate. Así mismo la posibilidad se puede ampliar a una variedad de virus fitopatógenos, ya que esta plaga tiene la capacidad de ser vector en muchos cultivos y para una amplia variedad de virus. En tomate también hay un alto potencial para desarrollar variedades con altos niveles de Lycopeno, el cual se reporta como un poderoso anticancerígeno, actualmente instituciones como el Instituto Nacional de Aprendizaje (INA) y el Instituto Nacional de Innovación y Transferencia de Tecnología Agropecuaria (INTA) disponen de materiales promisorios.

- En arroz: modificar genes de resistencia a la sequía por medio de la identificación e implantación de la resistencia que le puede conferir la planta de la "resurrección" (Selaginella lepidophylla). Esta planta originaria de los desiertos de México comparte la ruta de resistencia a déficit hídrico en muchas especies vegetales por lo que se ha encontrado como una especie altamente potencial para transferir su secuencia de genes a diversos cultivos. Actualmente instituciones como el Centro de Investigaciones en Biología Celular y Molecular (CIBCM) de la UCR está comenzando a trabajar en esta línea.

- Frutas tropicales: la creación de colores de cáscara nuevos y atractivos en cultivos tropicales es clave para el país, ya que éstos, tienen una alta demanda en los mercados internacionales y son exclusivos de las 
regiones tropicales, tales cultivos son la papaya, mango, piña y banano.

- Pitahaya: se puede modificar la región genómica que confiera resistencia a Fusarium sp. y Enterobacter ormaechei (bacteria identificada en Costa Rica por Retana K. 2015, datos sin publicar) los cuales atacan severamente al cultivo de pitahaya (Hylocereus megalanthus). Inversamente se podría hacer a las enfermedades menos agresivas modificando su genoma y así con muchas enfermedades que lo permitan, tanto en este cultivo como en otros.

- Café: por la importancia que representa el cultivo de café en el país y el alto costo en el manejo de enfermedades, se puede modificar la resistencia hacia fitopatógenos como lo son el ojo de gallo (Mycena citricolor) y la roya (Hemileia vastatrix). También hay una gran posibilidad de sincronizar la floración a un evento ya que actualmente muchos productores tienen altos costos de producción al tener 3 o hasta 4 eventos de floración en el año.

- Cultivos ornamentales: actualmente Costa Rica exporta una gran cantidad de especies vegetales entre las cuales podría identificar los genes que expresan los colores, modificarlos y obtener colores nuevos para el mercado. Tal es el caso de la Caña India (Dracaena fragans var. massangeana), la cual tiene un ciclo muy largo, una floración difícil de inducir y por ende el mejoramiento genético convencional se dificulta. Otras especies de Dracaena spp. también podrían ser modificadas. Flores y esquejes que actualmente se exportan se pueden ver beneficiados al poder ofrecer nuevos colores $y$ combinaciones de los mismos, identificando los locus que codifican para la expresión de color, y con esto ofrecer una mayor variabilidad de productos al mercado.

- En cacao: para todos es bien conocida la susceptibilidad de este cultivo al hongo Monilia (Moniliophtora roreri), encontrando la secuencia de los genes que codifican para la resistencia podrían modificarse para hacer al cultivo más tolerante o incluso resistente.
Actualmente, instituciones como el Centro Agronómico Tropical de Investigación y Enseñanza (CATIE) trabajan por medio del mejoramiento genético convencional, sin embargo esta investigación puede tardar de 10-15 años en obtener una variedad con algún grado de resistencia.

- En banano: el mismo caso mencionado para el cultivo de cacao se puede aplicar para el cultivo de banano, para el control del hongo Sigatoka (Mycosphaerella fijiensis), el impacto en el control de esta enfermedad, no solamente se enfocaría en la reducción de costos, tendría un mayor impacto a nivel ambiental y social.

- En piña: el control de la floración es un carácter de difícil fijación por medio del mejoramiento convencional, CRISPR-Cas9 podría modificar la secuencia que codifica para la expresión de la floración y modificarla para expresarla en un periodo específico del cultivo y de esta forma lograr planificar mejor la producción, así como la reducción de pérdidas y una mayor rentabilidad en el cultivo. También en piña las repercusiones ambientales de la mosca Stomoxys calcitrans sobre la salud humana y la producción pecuaria podría ser un problema resuelto, esto se lograría disminuyendo la fertilidad de las hembras de esta mosca por modificación de sus genes.

Son múltiples las aplicaciones que puede lograrse con CRISPR-Cas9, sin embargo, deberán analizarse desde la importancia e impacto que puede causar en el sector agrícola.

\section{El futuro de CRISPR-Cas9}

El rápido progreso en el desarrollo de nuevas herramientas para la investigación en biología celular y molecular ha sido notorio, marcado por herramientas simples, versátiles y eficientes. De los sistemas diseñadores de nucleasas, CRISPR-Cas9 es por mucho el más amigable para el usuario y consumidor final. Está claro ahora que la utilidad de ésta tecnología para la modificación en locus específicos, está limitado 
solo por la imaginación, además en años venideros es esperable el debate acerca del mejor aprovechamiento de la agricultura orgánica, la convencional, la sostenible y la proveniente de la biotecnología, las cuales podrían enlazarse.

Como hemos visto, la comunidad científica y la población en general se encuentran ante una tecnología que va a despertar odio y pasiones. Que ya ha desatado una guerra por los derechos de uso de la patente. Pero, sobre todo, la CRISPR/Cas9 ha cambiado la forma en la que vemos el futuro de la agricultura y la biotecnología convirtiendo a estos dos conceptos en un binomio matrimonial inseparable.

Veremos que nos depara el futuro...

\section{Referencias Bibliográficas}

Acevedo-García, J., Spencer, D., Thieron, H., Reinstadler, A., Hammond-Kosack, K., Phillips, A.L., Panstruga, R. (2016). Mlo-based powdery mildew resistance in hexaploid bread wheat generated by a non-transgenic tilling approach. Plant Biotechnology Journal. 15(3): 367-378.

Barrangou, R., Fremaux, C., Deveau, H., Richards, M., Boyaval, P., Moineau, S., Romero, D.A., Horvath, P. (2007). CRISPR provides acquired resistance against viruses in prokaryotes. Science (315): 1709-1712.

Beal, W.J. (1880). Indian corn. Michigan State Board of Agriculture. Michigan, USA. Annual Report (19): 279-289.

Bernal-Franco, D. (2015) (en línea). CRISPR: una herramienta para editar el genoma que está revolucionando la ciencia. Biogenic. Biologos Genetistas Colombianos. Consultado el día 17 de julio de 2017. Disponible en: http://biogenic-colombia.blogspot. com/2015/10/crispr-una-herramienta-para-editar-el. html

Bolivar, F., Rodriguez, R.L., Greene, P.J., Betlach, MC., Heyneker, H.L., Boyer, H.W., Crosa, J.H., Falkow, S. (1977). Construction and characterization of new cloning vehicles. II. A multipurpose cloning system. Gene. (2): 95-113.

Brouns, S.J., Jore, M.M., Lundgren, M., Westra, E.R., Slijkhuis, R.J., Snijders, A.P., Dickman, M.J., Makarova, K.S., Koonin, E.V., van der Oost, J. (2008).
Small. CRISPR RNAs guide antiviral defense in prokaryotes. Science. 2008 (321): 960-964.

Bullis, K. (2015) (en línea). Supercharged photosynthesis: advanced genetics tools could help boost cropyields and feed billions more people. MIT Technology Review. Consultado el día 14 de julio de 2017. Disponible en: https://www.technologyreview.com/s/535011/ supercharged-photosynthesis/\#comments

Ceccon, E. (2008). La Revolución Verde: tragedia en dos actos. Ciencias (91): 20-29p.

Dciencia (2015) (En línea). ¿Qué es la tecnología CRISPR/ Cas9 y cómo nos cambiaría la vida? Consultado el día 11 de julio de 2017. Disponible en: http://dciencia.es/ que-es-la-tecnologia-crispr-cas9/

FAO (1996) (En línea). Enseñanzas de una nueva Revolución Verde: hacia una nueva Revolución Verde. Consultado el día 11 de julio de 2017. Disponible en: http://www.fao.org/docrep/003/w2612s/w2612s06. htm

Freebairn, D.K. (1995). "Did the green revolution concentrate incomes? A quantitative study of research reports". World Development (23) 265-279.

Echarri, L. (1998) (En línea). Ciencias de la tierra y del medio ambiente. Tema 6: Alimentos y agua para una población creciente. Libro en línea. Consultado el día 11 de julio de 2017. Disponible en: http://www4. tecnun.es/asignaturas/Ecologia/Hipertexto/06Recurso s/120RevVerde.htm

Eckholm, E. (1978). Disappearing species. The social challenge. Washington, Worldwatch Institute, Worldwatch Paper, núm. 22. FAO. (1969). The green revolution. Genetic blacklash. Ceres. The FAO Review, sep./oct.

Garneau, J.E., Dupuis, M.E., Villion, M., Romero, D.A., Barrangou, R., Boyaval, P., Fremaux, C., Horvath, P., Magadán, A.H., Moineau, S. (2010). The CRISPR/ Cas bacterial immune system cleaves bacteriophage and plasmid DNA. Nature. (468) 67-71.

Haft, D.H., Selengut, J., Mongodin, E.F., Nelson, K.E. (2005). A guild of 45 CRISPR-associated (Cas) protein families and multiple CRISPR/Cas subtypes exist in prokaryotic genomes. PLOS Computational Biology. (1): e60. 
Hale, C.R., Zhao, P., Olson, S., Duff, M.O., Graveley, B.R., Wells, L., Terns, R.M., Terns, M.P. (2009). RNAguided RNA cleavage by a CRISPR RNA-Cas protein complex. Cell. (139): 945-956.

Hobbs, B. (2016) (en línea). CRISPR: The new tool in the gene editing revolution explained. ABC periódico en línea. News, Science. Consultado el día 12 de julio de 2017. Disponible en: http:// www.abc.net.au/news/science/2016-04-07/ crispr-gene-editing-technology-explainer/7217782

Jinek, M., Chylinski, K., Fonfara, I., Hauer, M., Doudna, J.A., Charpentier, E. (2012). A programmable DualRNA-Guided DNA Endonuclease in Adaptative Bacterial Inmmunity. Science 337 (6096): 816-821.

Jones, D.F. (1918). The effects of inbreeding and crossbreeding upon development. Connecticut Agriculture Experimental Station Bulletin. (207): 5-100.

Mali, P., Yang, L., Esvelt, K.M., Aach, J., Guell, M., Dicarlo, J.E., Norville, J.E., Church G.M. (2013). RNA-Guided human genome engineering via Cas9. Science. 339 (6121): 823-826.

Marraffini, L.A., Sontheimer, E.J. (2008). CRISPR interference limits horizontal gene transfer in staphylococci by targeting DNA. Science. 2008 (322): 1843-1845

Mojica, F.J., Diez-Villasenor, C., Garcia-Martinez, J., Soria, E. (2005). Intervening sequences of regularly spaced prokaryotic repeats derive from foreign genetic elements. Journal of Molecular Evolution. (60):174-182.

Opazo, J.G. (2016) (en línea). CRISPR, el futuro de la biotecnología agrícola. Huerta Digital, Agrosocial Media \& AgTech Magazine. Consultado el día 14 de julio de 2017. Disponible en: http://lahuertadigital.es/ crispr-biotecnologia-agricola/

Pul, U., Wurm, R., Arslan, Z., Geissen, R., Hofmann, N., Wagner, R. (2010). Identification and characterization of $E$. coli, CRISPR-cas promoters and their silencing by H-NS. Molecular Microbiology. (75): 1495-1512

Regalado, A. (2015) (en línea). Una patata con un solo gen silenciado podría revolucionar los OMG. MIT
Technology Review. Consultado el día 14 de julio de 2017. Disponible en: https://www.technologyreview. es/s/4852/una-patata-con-un-solo-gen-silenciado-podria-revolucionar-los-omg

Reis, A., Hornblowe, B., Robb, B., Tzertzinis, G. (2014) (En línea). CRISPR/Cas9 and targeted genome editing: A new era in molecular biology. New England Biolabs Inc. Consultado el 12 de julio de 2017. Disponible en: https://www.neb.com/tools-and-resources/featurearticles/crispr-cas9-and-targeted-genome-editing-anew-era-in-molecular-biology

Retana, K. (2015). Diagnóstico de enfermedades en el cultivo de pitahaya (Hylocereus megalanthus). Datos sin publicar. Comunicación personal. 2017.

Sapranauskas, R., Gasiunas, G., Fremaux, C., Barrangou, R., Horvath, P., Siksnys, V. (2011). The Streptococcus thermophilus CRISPR/Cas9 system provides immunity in Escherichia coli. Nucleic Acids Research. 39 (21): 9275-9282.

Shull, G.H. (1908). The composition of a field of maize. American Breeding Association Report. (4): 296-301.

Shull, G.H. (1909). A pure-line method of corn breeding. American Breeding Association Report. (5): 51-59.

Soyk, S., Lemmon, Z.H., Oved, M., Fisher, J., Liberatore, K.L., Park, S.J., Goren, A., Jiang, K., Ramos, A., van deer Knaap, E., van Eck, J., Zamir, D., Eshed, Y., Lippman, Z.B. (2017). Bypassing Negative Epistasis on Yield in Tomato Imposed by a Domestication Gene. Cell. 169(6): 1142-1155.

Specter, M. (2016) (en línea). How the DNA revolution is changing us? National Geographic Magazine. Edición, agosto de 2016. Consultado el día; 13 de Julio de 2017. Disponible en: http:// www.nationalgeographic.com/magazine/2016/08/ dna-crispr-gene-editing-science-ethics/

Wang, Y., Cheng, X. Shan, Q., Zhang, Y., Liu, J., Gao, C., Qiu, J. (2014). Simultaneous editing of three homoalleles in hexaploid bread wheat confers heritable resistance to powdery mildew. Nature Biotechnology. 32: 947-951. 